\title{
Effects of air pollution and climatology on COVID-19 mortality in Spain
}

\author{
Carlos Sanchez-Piedra ${ }^{1} \cdot$ Copytzy Cruz-Cruz ${ }^{2} \cdot$ Ana-Estela Gamiño-Arroyo $^{3} \cdot$ Francisco-Javier Prado-Galbarro $^{2} \mathbb{0}$
}

Received: 26 December 2020 / Accepted: 29 June 2021 / Published online: 26 July 2021

(c) The Author(s), under exclusive licence to Springer Nature B.V. 2021

\begin{abstract}
The health, economic, and social impact of COVID-19 has been significant across the world. Our objective was to evaluate the association between air pollution (through $\mathrm{NO}_{2}$ and $\mathrm{PM}_{2.5}$ levels) and COVID-19 mortality in Spanish provinces from February 3, 2020, to July 14, 2020, adjusting for climatic parameters. An observational and ecological study was conducted with information extracted from Datadista repository (Datadista, 2020). Air pollutants $\left(\mathrm{NO}_{2}\right.$ and $\mathrm{PM}_{2.5}$ levels) were analyzed as potential determinants of COVID-19 mortality. Multilevel Poisson regression models were used to analyze the risk of mortality after severe acute respiratory syndrome coronavirus 2 (SARS-CoV-2) infection. Models were adjusted by four climatic variables (hours of solar radiation, precipitation, daily temperature and wind speed) and population size. The mean levels of $\mathrm{PM}_{2.5}$ and $\mathrm{NO}_{2}$ across all provinces and time in Spain were $8.7 \mu \mathrm{g} / \mathrm{m}^{3}$ (SD 9.7) and $8.7 \mu \mathrm{g} / \mathrm{m}^{3}$ (SD 6.2), respectively. High levels of $\mathrm{PM}_{2.5}$ (IRR $\left.=1.016,95 \% \mathrm{CI}: 1.007-1.026\right), \mathrm{NO}_{2}(\mathrm{IRR}=1.066,95 \% \mathrm{CI}: 1.058-1.075)$ and precipitation ( $\mathrm{IRR}_{\mathrm{NO} 2}=0.989,95 \%$ CI: $0.981-0.997$ ) were positively associated with COVID-19 mortality, whereas temperature $\left(\mathrm{IRR}_{\mathrm{PM} 2.5}=0.988,95 \%\right.$ CI: 0.976-1.000; and $\mathrm{IRR}_{\mathrm{NO} 2}=0.771,95 \% \mathrm{CI}: 0.761-0.782$, respectively) and wind speed $\left(\mathrm{IRR}_{\mathrm{NO} 2}=1.095,95 \%\right.$ CI: 1.061-1.131 $)$ were negatively associated with COVID-19 mortality. Air pollution can be a key factor to understand the mortality rate for COVID-19 in Spain. Furthermore, climatic variables could be influencing COVID19 progression. Thus, air pollution and climatology ought to be taken into consideration in order to control the pandemic.
\end{abstract}

Keywords SARS-CoV-2 $\cdot$ COVID-19 $\cdot$ Mortality $\cdot$ Risk factors $\cdot$ Air pollution

\section{Introduction}

On December 31, 2019, the Municipal Health Commission in Wuhan (Hubei province, China) reported 27 cases of pneumonia of unknown etiology that included seven serious cases, with common exposure to a seafood, fish, and live animal wholesale market located in Wuhan city (Isolate and Wuhan-Hu-1, 2020). Onset of symptoms of the first case occurred on December 8, 2019. On January 7, 2020, Chinese authorities identified a new type of virus of the

Francisco-Javier Prado-Galbarro

frjavipg@gmail.com

1 Research Unit, Spanish Society of Rheumatology, Madrid, Spain

2 Orphan Drug Laboratory, Biologic System Department, Metropolitan Autonomous University, Calzada del Hueso 1100, Coapa, Villaquietud, Coyoacán, 04960 Mexico City, Mexico

3 Hospital Infantil de México Federico Gómez, Mexico City, Mexico
Coronaviridae family as the agent causing of the outbreak. Named as Severe Acute Respiratory Syndrome Coronavirus 2 (SARS-CoV-2), this new virus is the pathogen responsible for this infectious respiratory disease called Coronavirus Disease 2019 (COVID-19). On March 11, the World Health Organization (WHO) declared the COVID-19 pandemic.

Studies on past coronavirus outbreaks highlighted the impact of meteorological conditions in the virus dissemination (Casanova et al. 2010). The transmission of SARS$\mathrm{CoV}-2$ by aerosol is under consideration (Doremalen et al. 2020). This mechanism of spreading can be affected by climatology and air quality conditions. Setti et al. demonstrated that air pollution can contribute to spread the disease (Setti et al. 2020). Moreover, air pollution was studied as a key factor in leading to a more severe form of the disease (Cui et al. 2003). Recent studies assessed the impact of air quality in the spread and consequences of the COVID-19 pandemic (Wu et al. 2020). Some of these works evaluated the changes in air pollution due to traffic restrictions (Briz-Redón et al. 2020; Baldasano 2020) and how these modifications can have contributed to a reduction in mortality by COVID-19 
(Chen et al. 2020; Achebak et al. 2020; Urrutia-Pereira et al. 2020).

All these investigations met in pointing out the importance of air pollution and climatic parameters in the evolution of the pandemic. However, the connection between air quality, climatological (e.g., the impact of wind), and epidemiological variables, as well as the long-term impact of these parameters, are still controversial (Fattorini and Regoli 2020). In this study, we examined the association between air pollution and COVID-19 mortality in Spanish regions, adjusting for climatic parameters. Studying these factors and associations could be useful to a better understanding about the importance of air quality in terms of severity and mortality of the disease. We hypothesized that residents living in regions with higher long-term exposure to high concentrations of air pollutants would experience more severe COVID-19 outcomes, thus resulting in a higher mortality among more heavily polluted provinces.

\section{Methods}

\section{Sample}

This study was based on mortality data from Spanish provinces (groups of municipalities). The analysis included data from February 3, 2020, to July 14, 2020. We obtained the number of daily deaths from the Datadista repository (Datadista, 2020), which captures COVID-19 statistics data (ordered by days and Spanish regions) from the Ministerio de Sanidad, Consumo y Bienestar Social.

$\mathrm{PM}_{2.5}$ (22 units) and $\mathrm{NO}_{2}$ (50 units) levels were available from the Andalusian Office of Agriculture, Livestock, Fisheries, and Sustainable Development (Junta de Andalucía, 2020) for the different Andalusian monitoring stations and from the European Air Quality Portal (European Environment Agency, 2020) for the rest of the Spanish monitoring stations. These data were processed by DatAC, which is a visual analytics platform to explore air quality and climatic indicators.

\section{Outcome}

The outcome of this work was the number of COVID19 deaths per day in Spanish provinces. Considering that the mean incubation period of COVID 19 infection was 6 days (China 2019) and the average time from onset of symptoms to death was 18 days (Verity et al. 2020), we estimated 24 days as the average time from the infection to death. Therefore, daily deaths were accordingly moved back 24 days based on the estimation of the probable date of infection.

\section{Exposures}

\section{Air pollution}

We obtained air quality data from DatAC (available at https://covid19.genyo.es). We used daily mean concentrations of $\mathrm{NO}_{2}$ in 50 provinces, a traffic-related air pollutant, and a major component of urban smog, and of $\mathrm{PM}_{2.5}$ in 22 provinces, a heterogeneous mixture of fine particles in the air.

\section{Other variables}

Climatic and population variables such as temperature $\left({ }^{\circ} \mathrm{C}\right.$ ), precipitation (measured in liters per square meter, $1 / \mathrm{m} 2$ ), wind speed (meters per second, $\mathrm{m} / \mathrm{s}$ ), and insolation (hours) for each province were also downloaded from DatAC (available at https://covid19.genyo.es). Population information was obtained from the Spanish Statistics Institute (INE), updated on January 1, 2020.

\section{Statistical analysis}

We described daily average levels of $\mathrm{NO}_{2}$ and $\mathrm{PM}_{2.5}$ in tertiles, over the period from February 3 to July 14, 2020. The estimation of the variability of air pollution and mortality across time within each province was explored through a multilevel model with daily repeat province $\mathrm{PM}_{2.5}$ or $\mathrm{NO}_{2}$, including random effects for each region.

For a Poisson distributed variable $Y_{i}$, if the variance is greater than the mean, then over-dispersion is present. Given over-dispersion in mortality data, we applied a negative-binomial regression model to estimate the association of $\mathrm{PM}_{2.5}$ and $\mathrm{NO}_{2}$ trends with the number of deaths using a log link function. The model used was as follows:

$\log \left(Y_{i j}\right)=\beta_{0}+\sum_{k=1}^{n} \beta_{k} X_{k i}+\sum_{l=1}^{m} \beta_{l} z_{l j}+\log \left(T_{l}\right)+u_{j}$

$Y_{i j}$ is the number of deaths per day for day $i$ in the province $\mathrm{j}, \beta_{0}$ represents the intercept, and $\beta_{\mathrm{k}}$ represents the percentage of change from baseline for $\mathrm{NO}_{2}, \mathrm{PM}_{2.5}$, and each climatic parameter (temperature, precipitation, wind speed, and hours of solar radiation). $\beta_{1}$ is the vector of random effects for the sample variables $Z_{1} X_{i}$ is the set of explanatory variables at the individual level (level 1 ), and $Z_{j}$ is the set of explanatory variables defined for the provinces (level 2), being $u_{j}$ the residuals of level 2, for which it is assumed that they are independent and follow a normal distribution with mean 0 and variance $\sigma_{u}^{2}$. And $\log \left(\mathrm{T}_{1}\right)$ is the number of inhabitants of each province as an offset term. 
A null model was fitted to estimate the median odds ratio (MOR), which is a measure of the variation of mortality across different provinces that is not explained by the modeled factors. It was obtained with the following formula:

$M O R=\exp \left[\sqrt{\left(2 * V_{A}\right)} * 0.6745\right] \approx \exp \left(0.95 \sqrt{V_{A}}\right)$

$\mathrm{V}_{\mathrm{A}}$ is the province-level variance. If the MOR is 1, there is no variation between municipalities; a larger MOR indicates considerable between-province variation.

We estimated whether increases in $\mathrm{NO}_{2}$ and $\mathrm{PM}_{2.5}$ were associated with changes in mortality over time by using mixed-effects models (with random effects for provinces). For $\mathrm{NO}_{2}$ and $\mathrm{PM}_{2.5}$, a set of adjusted models were then fitted separately for each climatic parameter. A final model, including all climatic variables from the previous step plus the offset term, was fitted for $\mathrm{NO}_{2}$ and $\mathrm{PM}_{2.5}$, separately.

We used z-score transformation to compare levels of PM2.5 and NO2 and climatic variables with the number of daily deaths. This transformation was successfully used as a normalization procedure. A z-score is the result of dividing the amount that a raw score differs from the mean of the distribution by the standard deviation.

We used Stata 14.0 (StataCorp, Stata Statistical Software, 2015) for the data analysis. The significance level was set at 0.05 .

\section{Results}

Table 1 summarizes the daily average concentrations of $\mathrm{PM}_{2.5}$ by tertiles over the study period. The mean $\mathrm{PM}_{2.5}$ across all provinces and time was $8.7 \mu \mathrm{g} / \mathrm{m}^{3}$ (SD 9.7). The mean mortality across all provinces and time was 4.8 deaths (SD 20.4). Provinces with higher levels of $\mathrm{PM}_{2.5}$ tended to have more hours of solar radiation, less precipitation and wind speed, and higher population size than those with lower levels. A description of the compiled data by provinces is shown in Supplementary Table S1.

Table 2 summarizes daily average concentrations of $\mathrm{NO}_{2}$ by tertiles over the study period. The mean of $\mathrm{NO}_{2}$ concentration across all provinces and time was $8.7 \mu \mathrm{g} / \mathrm{m}^{3}$ (SD 6.2). Provinces with higher levels of $\mathrm{NO}_{2}$ were associated with more hours of solar radiation, less precipitation and wind
Table 1 Characteristics of provinces by tertiles of average of $\mathrm{PM}_{2.5}$ over the period from February 3rd to July 14th, 2020
Table 2 Characteristics of provinces by tertiles of average of $\mathrm{NO}_{2}$ over the period from February 3rd to July 14th, 2020

\begin{tabular}{|c|c|c|c|c|c|}
\hline \multirow[t]{2}{*}{ Variables, mean (SD) } & \multirow[t]{2}{*}{ Total } & \multicolumn{3}{|c|}{ Daily average concentrations of $\mathrm{PM}_{2.5}$} & \multirow[t]{2}{*}{ P-value } \\
\hline & & $<5.7 \mu \mathrm{g} / \mathrm{m} 3$ & $\begin{array}{l}\geq 5.7 \\
\text { and }<9.12 \mu \mathrm{g} / \\
\text { m3 }\end{array}$ & $\geq 9.12 \mu \mathrm{g} / \mathrm{m} 3$ & \\
\hline Deaths & $4.8(20.4)$ & $5.6(28)$ & $5.8(22.5)$ & $8.6(29.2)$ & $<0.001$ \\
\hline PM 2.5 & $8.7(9.7)$ & $4.1(1.1)$ & $7.3(1)$ & $14.7(14.9)$ & $<0.001$ \\
\hline Hours of solar radiation & $7.8(4.1)$ & $6.8(4.1)$ & $7.3(4.1)$ & $7.9(4)$ & $<0.001$ \\
\hline Rainfall & $1.8(4.6)$ & $2.3(5)$ & $2.1(5.2)$ & $1.2(3.4)$ & $<0.001$ \\
\hline Temperature & $16.3(5.4)$ & $15.5(4.7)$ & $15.4(4.6)$ & $16(5.3)$ & 0.241 \\
\hline Wind speed & $3(1.3)$ & $3.3(1.4)$ & $3.1(1.4)$ & $3(1.3)$ & $<0.001$ \\
\hline $\begin{array}{r}\text { Population size (per } \\
100,000 \text { residents) }\end{array}$ & $9.3(12.2)$ & $10.3(12.2)$ & $11.8(14.8)$ & $12.0(15.2)$ & 0.006 \\
\hline
\end{tabular}

\begin{tabular}{|c|c|c|c|c|c|}
\hline \multirow[t]{2}{*}{ Variables, mean (SD) } & \multirow[t]{2}{*}{ Total } & \multicolumn{3}{|c|}{ Daily average concentrations of $\mathrm{NO}_{2}$} & \multirow[t]{2}{*}{ P-value } \\
\hline & & $<5.46 \mu \mathrm{g} / \mathrm{m} 3$ & $\begin{array}{l}\geq 5.46 \\
\text { and }<8.95 \mu \mathrm{g} / \\
\mathrm{m} 3\end{array}$ & $\geq 8.95 \mu \mathrm{g} / \mathrm{m} 3$ & \\
\hline Deaths & $4.8(20.4)$ & $1.9(4.1)$ & $2.9(10.4)$ & $10.4(33.8)$ & $<0.001$ \\
\hline $\mathrm{NO} 2$ & $8.7(6.2)$ & $3.8(1.1)$ & $7(1)$ & $15.2(6.8)$ & $<0.001$ \\
\hline Hours of solar radiation & $7.8(4.1)$ & $7(4)$ & $7.6(4.1)$ & $8.1(3.9)$ & $<0.001$ \\
\hline Rainfall & $1.8(4.6)$ & $2.4(5.1)$ & $1.9(4.6)$ & $1.3(4.2)$ & $<0.001$ \\
\hline Temperature & $16.3(5.4)$ & $15.1(4.6)$ & $16.2(5.2)$ & $15.9(5.6)$ & $<0.001$ \\
\hline Wind speed & $3(1.3)$ & $3.1(1.3)$ & $3(1.3)$ & $2.8(1.2)$ & $<0.001$ \\
\hline $\begin{array}{l}\text { Population size (per } \\
100,000 \text { residents) }\end{array}$ & $9.3(12.2)$ & $5.8(5.3)$ & $8.4(9.2)$ & $14.7(17.3)$ & $<0.001$ \\
\hline
\end{tabular}


speed, and higher population size than those with lower levels. Temperature was high in tertile 2 and we inferred that it had a positive correlation with mortality. A description of the compiled data by provinces is shown in Supplementary Table S2.

Figure 1 shows the evolution of the daily number of deaths moved back 24 days, daily levels of $\mathrm{PM}_{2.5}$ and $\mathrm{NO}_{2}$, and climatic variables (the quantities were standardized to be comparable), and we compared z-scores of $\mathrm{PM}_{2.5}$ and $\mathrm{NO}_{2}$, and climatic variables with $\mathrm{z}$-scores of the number of deaths.

Table 3 shows the association of daily mortality changes with $\mathrm{PM}_{2.5}$, adjusted for climatic parameters (hours of solar radiation, precipitation, temperature, and wind speed). The increase in one $\mu \mathrm{g} / \mathrm{m}^{3}$ of $\mathrm{PM}_{2.5}$ was associated with $1.6 \%$ more mortality (IRR $=1.016,95 \%$ CI: $1.007-1.026$ ). However, the increase in temperature was associated with $1.2 \%$ (IRR $=0.988,95 \%$ CI: $0.976-1.000)$ less mortality for COVID-19.

Table 4 presents the results of the multilevel model to estimate the association between mortality and $\mathrm{NO}_{2}$,
Table 3 Adjusted associations between mortality and $\mathrm{PM}_{2.5}$

\begin{tabular}{lll}
\hline Predictors & \multicolumn{2}{l}{ Effect of $\mathrm{PM}_{2.5}$ on mortality** } \\
\hline & OR & $95 \% \mathrm{CI}$ \\
$\mathrm{PM}_{2.5}$ & $1.016^{*}$ & $1.007-1.026$ \\
Hours of solar radiation & 1.005 & $0.986-1.025$ \\
Precipitation & $0.988^{*}$ & $0.976-1.000$ \\
Temperature & $0.762^{*}$ & $0.747-0.777$ \\
Wind speed & 1.036 & $0.994-1.080$ \\
\hline
\end{tabular}

* Significant values $(p<0.05)$

** All the models were adjusted by the population size

adjusted for climatic parameters (hours of solar radiation, precipitation, temperature, and wind speed). The increase in one $\mu \mathrm{g} / \mathrm{m}^{3}$ of $\mathrm{NO}_{2}$ levels was associated with a $6.6 \%$ increase in mortality for COVID-19 (IRR $=1.066,95 \%$ CI: $1.058-1.075)$. Also, the increase in precipitation $\left(1 / \mathrm{m}^{2}\right)$ and temperature $\left({ }^{\circ} \mathrm{C}\right)$ levels were associated with a lower risk of COVID-19 mortality (IRR precipitation $=0.989$,
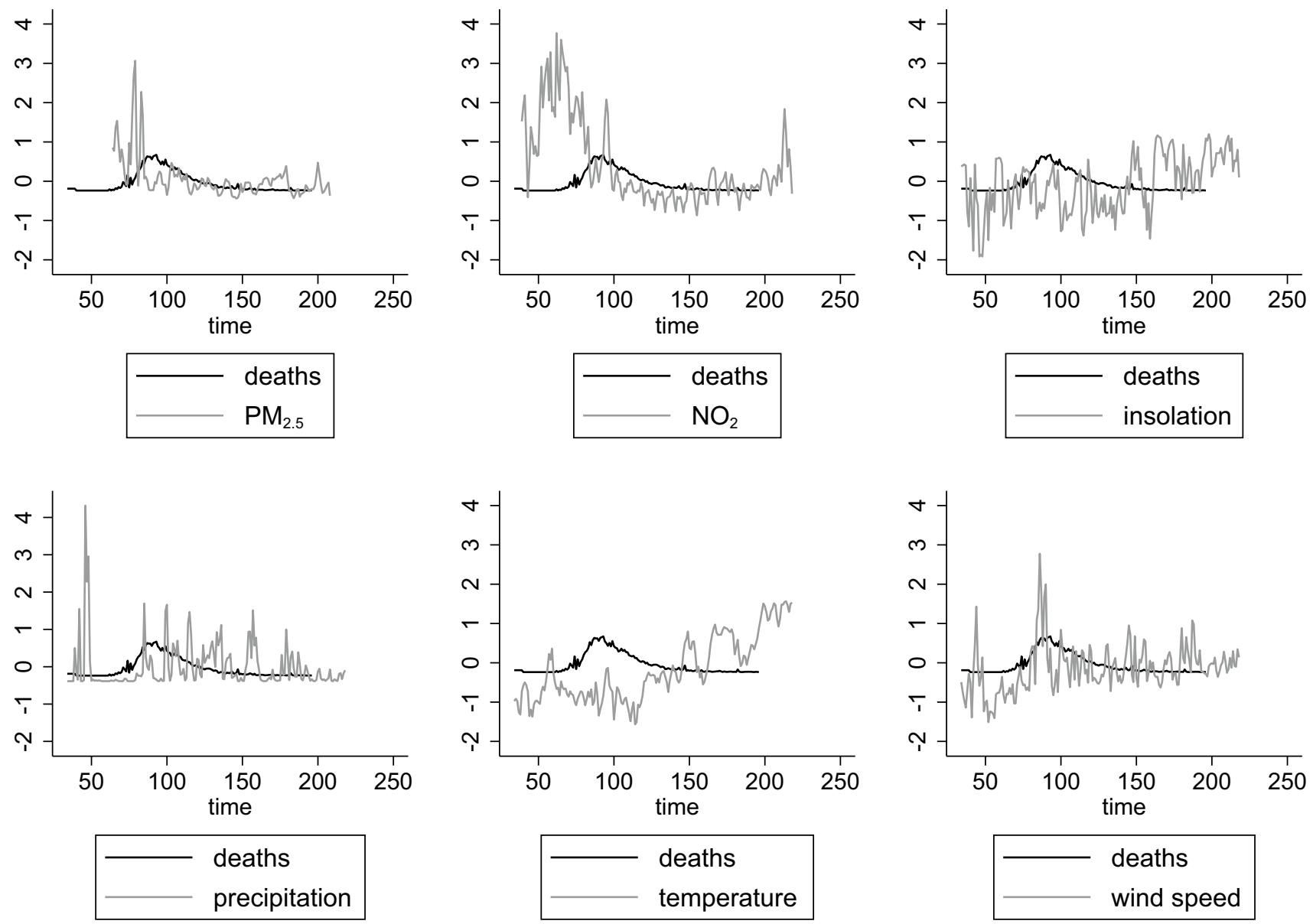

Fig. 1 Z-scores (on $\mathrm{Y}$ axis) of fluctuations in $\mathrm{PM}_{2.5}, \mathrm{NO}_{2}$ and climatic parameters, and in daily deaths estimated by possible day of infection $(\mathrm{t}+24$ days $)$ 
Table 4 Adjusted associations between mortality and $\mathrm{NO}_{2}$

\begin{tabular}{llr}
\hline Predictors & & Effect of $\mathrm{NO}_{2}$ on mortality** \\
\hline & OR & $95 \% \mathrm{CI}$ \\
$\mathrm{NO}_{2}$ & $1.066^{*}$ & $1.058-1.075$ \\
Hours of solar radiation & 0.994 & $0.981-1.008$ \\
Precipitation & $0.989^{*}$ & $0.981-0.997$ \\
Temperature & $0.771^{*}$ & $0.761-0.782$ \\
Wind speed & $1.095^{*}$ & $1.061-1.131$ \\
\hline
\end{tabular}

* Significant values $(p<0.05)$

** All the models were adjusted by the population size

95\% CI: 0.981-0.997; IRR temperature $=0.771,95 \%$ CI: $0.761-0.782$, respectively). Wind speed $(\mathrm{m} / \mathrm{s})$ was associated with a $9.5 \%$ increase (IRR $=1.095,95 \%$ CI: $1.061-1.131)$ in COVID-19 mortality.

\section{Discussion}

The most relevant finding of this work was a significant association between air pollution levels and increases in mortality in Spanish provinces, after considering climatic parameters (temperature, insolation, precipitation, wind speed). This finding was driven by an association of increases in $\mathrm{PM}_{2.5}$ and $\mathrm{NO}_{2}$ levels with increases in COVID-19 mortality. Temperature and wind speed were key factors to understand COVID-19 lethality.

The impact of pollutants on fatality caused by the SARSCoV2 was studied previously (Ali and Islam xxxx). We found an association between $\mathrm{NO}_{2}$ levels and COVID-19 mortality in Spain. Ogen et al. demonstrated that European regions with the highest $\mathrm{NO}_{2}$ concentrations were associated with the highest mortality ratios (Ogen 2020). This work also studied the impact of airflow on the severity of the infection and found that downwards airflow, which prevents efficient dispersion of air pollution, could be associated with fatality. However, these results are still controversial due to methodological limitations (Pisoni and Dingenen 2020; Chudnovsky 2020). Wind speed was evaluated in our $\mathrm{NO}_{2}$ model and we found no association with COVID-19 mortality. The effect of $\mathrm{NO}_{2}$ concentration over deaths caused by COVID-19 was studied in other regions. Pacheco et al. found a strong correlation between air $\mathrm{NO}_{2}$ concentrations and the cases/mortality caused by COVID-19 in Ecuador (Pacheco et al. 2020). Another analysis from India suggests that exposure to $\mathrm{NO}_{2}$ may increase the COVID-19 pandemic fatality (Chakraborty et al. 2020). A work aimed at analyzing the association between COVID-19 evolution and the air quality index, comorbidities, and sociodemographic factors in the USA found that $\mathrm{NO}_{2}$ levels could be one of the key factors to understand COVID-19 susceptibility and mortality
(Sarmadi et al. 2020). In particular, Marques et al. described and studied the effect of $\mathrm{PM}_{10}, \mathrm{NO}_{2}$, and $\mathrm{O}_{3}$ on COVID19 infection in Catalonia (Spain). They found a potential association between air pollution and COVID-19 outcomes (Marquès et al. xxxx).

The role of PM2.5 levels is still controversial. We found an association with COVID-19 mortality. This was not found in previous works based on England data. Konstantinoudis et al. showed a strong effect of long-term $\mathrm{NO}_{2}$ exposure on COVID-19; however, this work did not find evidence about an association between $\mathrm{PM}_{2.5}$ and COVID-19 mortality (Konstantinoudis et al. 2020). There was no evidence of a significant association between $\mathrm{PM}_{2.5}$ and COVID-19 mortality in a multivariate analysis from Bray et al. (Bray et al. 2020). However, Zoran et al. found similar results; there was a strong association between COVID-19 daily new cases and $\mathrm{PM}_{2.5}$ levels in Italy (Zoran et al. 2020). Evidence from the Netherlands suggested that $\mathrm{PM}_{2.5}$ was a highly significant predictor of COVID-19-related hospital admissions (Andree 2020). Other preliminary studies pointed out that $\mathrm{PM}_{2.5}$ levels may be affecting disease evolution, according to available data in areas with worse prior air quality (Hendryx and Luo 2020). All investigations agree on the need to continue evaluating the role of $\mathrm{PM}_{2.5}$ levels in the evolution of COVID-19. Some previous works found that COVID-19 mortality presented geographical differences, especially when the analysis considered data from urban and rural areas (Fattorini and Regoli 2020; Marquès et al. 2020). This finding may be partially explained considering the effect of air pollution in more industrialized cities. With regard to other climatic factors related to COVID-19 mortality, our findings are consistent with a growing body of evidence suggesting that these variables are essential to understand the pandemic. We found a negative association between temperature and mortality. This finding is similar to the results of Ma et al. in China (Ma et al. 2020). This work found that the temperature variation may be one key factor affecting the death rate caused by COVID-19. Temperature was also associated with the apparition of new confirmed cases related to COVID-19 in the USA, although there was 
no evidence about the connection between temperature and COVID-19 mortality (Adhikari and Yin 2020; Bashir et al. 2020). A study based on a machine learning approach demonstrated that the higher the value of temperature, the lower the number of infection cases, confirming the relevance of temperature in the spread of the virus (Malki et al. 2020). Regarding the role of wind speed in COVID-19 outcomes, the existing evidence is controversial (Bashir et al. 2020; Şahin 2020; Ahmadi et al. 2020).

This study has strengths and limitations. Firstly, we did not use information from COVID-19 case counts because they were underestimated. However, data from mortality have been used to estimate the association, as the underestimation is substantially lower for death counts than for case counts. Secondly, we lack data to know the long-term exposure levels of $\mathrm{PM}_{2.5}$ and $\mathrm{NO}_{2}$, but these levels in the period used can be considered as a proxy of urbanity. Finally, we could not take into account the number of hospitalized patients or patients in intensive care units with COVID-19, socio-economic and demographic characteristics, and information regarding comorbidities due to the lack of provincelevel data. However, although we controlled for climatic variables and population size, the exclusion of these variables did not vary the associations.

Our findings could have implications for the control and prevention of this disease. So that, this research could lead to a better knowledge of the effect of climatic parameters on COVID-19 spread, contributing to improve future public health strategies. Therefore, further extensive research is recommended to reach a more comprehensive understanding of the factors associated with COVID-19 mortality.

Supplementary Information The online version contains supplementary material available at https://doi.org/10.1007/s11869-021-01062-2.

Data availability The datasets generated during and/or analysed during the current study are available in:

(1) Air pollutants (NO2 and PM2.5 levels) and climatic variables: the DatAC repository, https://covid19.genyo.es.

(2) Mortality: https://github.com/datadista/datasets/tree/master/ COVID $\% 2019$.

\section{Declarations}

Conflict of interests The authors declared no potential conflicts of interest with respect to the research, authorship, and/or publication of this article.

\section{References}

Achebak H, Petetin H, Quijal-Zamorano M, Bowdalo D, García-Pando CP, Ballester J (2020) Reduction in air pollution and attributable mortality due to COVID-19 lockdown. Lancet Planet Health. 4(7):e268
Adhikari A, Yin J (2020) Short-Term Effects of Ambient Ozone, PM2. 5, and Meteorological Factors on COVID-19 Confirmed Cases and Deaths in Queens, New York. Int J Environ Res Pub Health. 17(11):4047

Ahmadi M, Sharifi A, Dorosti S, Ghoushchi SJ, Ghanbari N (2020) Investigation of effective climatology parameters on COVID-19 outbreak in Iran. Sci Total Environ. 138705

Ali N, Islam F (2020) The Effects of Air Pollution on COVID-19 Infection and Mortality-A Review on Recent Evidence. Front. Pub Health. 8:580057

Andree BPJ (2020) Incidence of COVID-19 and Connections with Air Pollution Exposure: Evidence from the Netherlands. The World Bank

Baldasano JM (2020) COVID-19 lockdown effects on air quality by NO2 in the cities of Barcelona and Madrid (Spain). Sci Total Environ. 741:140353.

Bashir MF, Ma B, Komal B, Bashir MA, Tan D, Bashir M (2020) Correlation between climate indicators and COVID-19 pandemic in New York, USA. Sci Total Environ. 138835

Bray I, Gibson A, White J (2020) Coronavirus disease 2019 mortality: a multivariate ecological analysis in relation to ethnicity, population density, obesity, deprivation and pollution. Publ Health 185:261-263

Briz-Redón Á, Belenguer-Sapiña C, Serrano-Aroca Á (2020) Changes in air pollution during COVID-19 lockdown in Spain: a multi-city study. J Environ Sci 101:16-26

Casanova LM, Jeon S, Rutala WA, Weber DJ, Sobsey MD (2010) Effects of air temperature and relative humidity on coronavirus survival on surfaces. Appl Environ Microbiol 76(9):2712-2717

Chakraborty P, Jayachandran S, Padalkar P et al (2020) Exposure to Nitrogen Dioxide (NO 2) from Vehicular Emission Could Increase the COVID-19 Pandemic Fatality in India: A Perspective. Bull Environ Contamin Toxicol 105(2):198-204

Chen K, Wang M, Huang C, Kinney PL, Anastas PT (2020) Air pollution reduction and mortality benefit during the COVID-19 outbreak in China. Lancet Planet Health 4(6):e210-e212

China W (2020) Report of the WHO-China joint mission on coronavirus disease 2019 (COVID-19). World Health Organization; Geneva, Switzerland. 2020.

Chudnovsky AA (2020) Letter to editor regarding Ogen Y 2020 paper:"Assessing nitrogen dioxide (NO2) levels as a contributing factor to coronavirus (COVID-19) fatality". Sci Total Environ

Cui Y, Zhang Z-F, Froines J et al (2003) Air pollution and case fatality of SARS in the People's Republic of China: an ecologic study. Environ Health 2(1):1-5

Datadista (2020) Datadista [WWW Document]. GitHub. https:// github.com/datadista. Accessed 28 Aug 2020

European Environment Agency (2020) European Air Quality Portal - e-Reporting. https://aqportal.discomap.eea.europa.eu/. Accessed 28 Aug 2020

Fattorini D, Regoli F (2020) Role of the chronic air pollution levels in the Covid-19 outbreak risk in Italy. Environ Pollut. 114732

Hendryx M, Luo J (2020) COVID-19 prevalence and fatality rates in association with air pollution emission concentrations and emission sources. Environ Pollut. 265:115126

Isolate WSMPV, Wuhan-Hu-1 (2020) Complete Genome

Junta de Andalucía (2020) Informes diarios de calidad del aire. Red de Información Ambiental de Andalucía. Consejería de Medio Ambiente y Ordenación del Territorio. Junta de Andalucía. [WWW Document]. http://www.juntadeandalucia.es/medioambiente/site/ rediam/. Accessed 28 Aug 2020

Konstantinoudis G, Padellini T, Bennett JE, Davies B, Ezzati M, Blangiardo M (2020) Long-term exposure to air-pollution and COVID19 mortality in England: a hierarchical spatial analysis. medRxiv 
Ma Y, Zhao Y, Liu J, et al (2020) Effects of temperature variation and humidity on the mortality of COVID-19 in Wuhan. medRxiv

Malki Z, Atlam E-S, Hassanien AE, Dagnew G, Elhosseini MA, Gad I (2020) Association between weather data and COVID-19 pandemic predicting mortality rate: Machine learning approaches. Chaos, Solitons \& Fractals. 138:110137

Marquès M, Rovira J, Nadal M, Domingo JL (2020) Effects of air pollution on the potential transmission and mortality of COVID19: A preliminary case-study in Tarragona Province (Catalonia, Spain). Environ Res. 192:110315

Ogen Y (2020) Assessing nitrogen dioxide (NO2) levels as a contributing factor to the coronavirus (COVID-19) fatality rate. Sci Total Environ. 138605

Pacheco H, Díaz-López S, Jarre E, Pacheco H, Méndez W, ZamoraLedezma E (2020) NO2 levels after the COVID-19 lockdown in Ecuador: A trade-off between environment and human health. Urban Clim. 34:100674

Pisoni E, Van Dingenen R (2020) Comment to the paper "Assessing nitrogen dioxide (NO2) levels as a contributing factor to coronavirus (COVID-19) fatality", by Ogen, 2020. Sci Total Environ. 738:139853.

Şahin M (2020) Impact of weather on COVID-19 pandemic in Turkey. Sci Total Environ. 138810

Sarmadi M, Moghanddam VK, Dickerson AS, Martelletti L (2020) Association of COVID-19 distribution with air quality, sociodemographic factors, and comorbidities: an ecological study of US states. Air Qual Atmos Health. 1-11
Setti L, Passarini F, De Gennaro G, et al (2020) The potential role of particulate matter in the spreading of COVID-19 in Northern Italy: First evidence-based research hypotheses. medRxiv

Urrutia-Pereira M, Mello-da-Silva C, Solé D (2020) COVID-19 and air pollution: A dangerous association? Allerg Et Immunopathol 48(5):496-499

Van Doremalen N, Bushmaker T, Morris DH et al (2020) Aerosol and surface stability of SARS-CoV-2 as compared with SARS-CoV-1. New England J Med 382(16):1564-1567

Verity R, Okell LC, Dorigatti I et al (2020) Estimates of the severity of coronavirus disease 2019: a model-based analysis. Lancet Infect Dis 20(6):669-677

Wu X, Nethery RC, Sabath BM, Braun D, Dominici F (2020) Exposure to air pollution and COVID-19 mortality in the United States. medRxiv

Zoran MA, Savastru RS, Savastru DM, Tautan MN (2020) Assessing the relationship between surface levels of PM2. 5 and PM10 particulate matter impact on COVID-19 in Milan, Italy. Sci Total Environ. 738:139825

Publisher's note Springer Nature remains neutral with regard to jurisdictional claims in published maps and institutional affiliations. 